\title{
DISERTACIONES
}

ENSAYOS

Para citar este artículo: Huertas, A. (2018). El estudio de las minorías como audiencia. El caso de la población migrante. Anuario Electrónico de Estudios en Comunicación Social "Disertaciones", 11(1), 40-55. Doi: http://dx.doi.org/10.12804/revistas.urosario.edu.co/disertaciones/a.6276

\section{EL ESTUDIO DE LAS MINORÍAS COMO AUDIENCIA. EL CASO DE LA POBLACIÓN MIGRANTE}

\section{The Study of Minorities as an Audience. The Case of Migrant Population}

\section{O estudo das minorias como audiência. O caso da população migrante}

Amparo Huertas Bailén, Universitat Autònoma de Barcelona (Catalunya-España) amparo.huertas@uab.cat

\section{Recibido: 25 de enero de 2017}

\section{RESUMEN}

Tras constatar la escasa dedicación que han recibido las minorías en el marco del estudio de las audiencias, se reúnen aquí las bases teóricas y metodológicas sobre las que se podría asentar una línea de trabajo que tratara de revertir esa tendencia. Este ensayo se divide en dos partes. En la primera, se propone una definición de la noción de minorías y a continuación se reflexiona sobre sus posibilidades de empoderamiento, de hacerse visibles frente a las diversas dimensiones de la globalización. En la segunda, se expone el modo en que se viene estudiando la población migrante como consumidora y usuaria de los medios de comunicación y de las tecnologías que les son próximas. El aumento de los movimientos migratorios, así como los cambios que se han producido a raíz de la evolución sociotecnológica y cultural han provocado un especial interés por el estudio de los grupos sociales migrantes. Con el paso del tiempo, la perspectiva transnacional ha ido mermando el poder del pensamiento colonial y al mismo tiempo el enfoque de género poco a poco va ganando peso. Pero, además de los planteamientos 


\title{
DISERTACIONES
}

Estudios de audiencias y recepción: audiencias minoritarias y nuevas mediaciones

ISSN: $1856-9536$

Doi: http://dx.doi.org/10.12804/revistas.urosario.edu.co/disertaciones/v11i1

Volumen 11, Número 1 / Enero-junio 2018

Versión PDF para imprimir desde

http://revistas.urosario.edu.co/index.php/disertaciones

teóricos, también se delinean los objetos de estudio con más presencia en las aproximaciones investigativas que vienen haciéndose sobre las migraciones desde la comunicación.

Palabras clave: minorías, audiencias, migración, transnacionalismo, género.

\begin{abstract}
After noting the lack of attention paid to minorities in audience studies, the authors present the theoretical and methodological bases on which a line of research to reverse this trend can be built. The essay is divided into two parts. In the first, a definition of minorities and possibilities for minority visibility and empowerment in the face of a varied globalization are discussed. In the second, the authors discuss how the migrant population is studied as consumers and media users, and the technologies that are close to them. The increase in migratory movement and social changes stemming from socio-cultural and technological evolution have stimulated a special interest in the study of migrant social groups. Over time, a transnational perspective has been undermining the power of colonial thought, and a gendered approach is gradually gaining weight. In addition to discussing theoretical approaches, the study foregrounds the objects of study in Communication research on migration.
\end{abstract}

Keywords: Minorities, audiences, migration, transnationalism, gender.

\section{RESUMO}

Após constatar a escassa dedicação que têm recebido as minorias no marco do estudo das audiências, reúnem-se aqui as bases teórico-metodológicas sobre as que se poderia assentar uma linha de trabalho que tentara reverter essa tendência. Este ensaio divide-se em duas partes. Na primeira, propõe-se uma definição da noção de minorias e, a continuação, se reflete sobre suas possibilidades de empoderamento, de se fazer visíveis frente às diversas dimensões da globalização. Na segunda, expõe-se o modo em que se vem estudando a população migrante como consumidora e usuária dos meios de comunicação e das tecnologias que lhes são próximas. 0 aumento dos movimentos migratórios, assim como as mudanças que se tem produzido a raiz da evolução sócio-tecnológica-cultural, tem provocado uma especial interesse pelo estudo dos grupos sociais migrantes. Com o passo do tempo, a perspectiva transnacional tem ido mermando o poder do pensamento colonial e, ao mesmo tempo, o enfoque de gênero pouco a pouco vai ganhando peso. Mas, para além das concepções teóricas, também delineia os objetos de estudo com mais presença nas aproximações investigativas que vêm se fazendo sobre as migrações desde a comunicação.

Palavras-chave: minorias, audiências, migração, transnacionalismo, gênero. 


\section{DISERTACIONES}

ENSAYOS

Estudios de audiencias y recepción: audiencias minoritarias y nuevas mediaciones

ISSN: 1856-9536

Doi: http://dx.doi.org/10.12804/revistas.urosario.edu.co/disertaciones/v11i1

Volumen 11, Número 1 / Enero-junio 2018

Versión PDF para imprimir desde

http://revistas.urosario.edu.co/index.php/disertaciones

\section{Introducción}

El estudio del comportamiento de las minorías ante los medios de comunicación, tanto como consumidores (perspectiva comercial) como en calidad de receptores (perspectiva académica), apenas ha sido abordado. La preocupación por ahondar en la función socializadora de los mass media ha derivado mayoritariamente en el desarrollo de investigaciones sobre el modo en que estos dan visibilidad a las identidades individuales y colectivas, a partir de estudios basados en el análisis de contenido de representaciones e imaginarios. Un artículo pionero en este sentido fue el publicado por Miquel Rodrigo Alsina en 1996 con el título "Minorías étnicas, identidades y medios de comunicación"; las propuestas más recientes nos revelan el peso que está adquiriendo el interés, por un lado, de la cuestión de los estereotipos -como queda reflejado en el trabajo de Patricia Izquierdo (2014) centrado en la etnia y el género en la publicidad-y, por otro, la construcción mediática de hechos noticiosos relevantes - un ejemplo es el trabajo de Fajardo y Soriano (2016) acerca de la migración en el Mediterráneo-. En consonancia con este planteamiento, se dispone de múltiples guías y recomendaciones éticas para un correcto tratamiento mediático de las minorías, cuya finalidad es ir más allá de los apartados específicos de los libros de estilo.

Por tanto, no resulta extraño comprobar que la historia que hemos tejido sobre el estudio de las audiencias apenas haya abordado la cuestión de las minorías (Huertas-Bailén, 2002). De hecho, ni la recurrente referencia a la brecha digital (Castells, 1997) ha venido acompañada de una sólida reflexión sobre estos grupos sociales. Primero se habló de las masas, de las multitudes, y la evolución sociotecnológica y cultural -siguiendo la terminología de Pierre Lévy- derivó en la observación del individuo. De la teoría de la aguja hipodérmica se pasó a dar importancia, con los estudios culturales de fondo, a los tipos de negociación que podían darse en el proceso de descodificación de los mensajes (Hall, Hobson, Love \& Wilis, 1981) o a la clasificación de las mediaciones (Martin-Barbero, 1998), por citar dos de los aspectos que más resonancia han alcanzado.

Si bien es cierto que con la multiplicación de la oferta y la búsqueda de nuevos mercados es un hecho incuestionable la fragmentación del público generalista en pequeños grupos definidos por perfiles sociodemográficos concretos o por el hecho de compartir intereses temáticos, esto no ha derivado en el estudio de las minorías como aquí las entendemos. En términos empresariales se habla de nichos o targets interesantes desde el punto de vista comercial; en el ámbito científico, de comunidades interpretativas (Lindlof, 1988) o de microgrupos (Lipovetsky, 2000), por citar algunas de las nociones de uso fuertemente consolidado.

Ahora bien, esta introducción quedaría incompleta si no aclaráramos que esta laguna tampoco debe interpretarse como una desconsideración absoluta hacia las minorías. Es más, sería un grave error no hacerlo. Precisamente uno de los objetivos sobre los que se fundamentan los sistemas públicos de comunicación es poner al alcance del conjunto de la ciudadanía -incluidas mayorías y minorías - todo tipo de contenidos mediáticos, entendidos estos como bienes que han de cubrir el conjunto de intereses sociales. Los medios de comunicación siempre se han considerado elementales para el desarrollo de los sistemas democráticos. Basta con recordar, por ejemplo, el importante papel que se les ha asignado en las luchas por conservar las lenguas minoritarias (Núñez de Prado, 2002; Huertas Bailén, 2015).

Asimismo, este eje de actuación, que normalmente se resume con la expresión "democratización de la información", tampoco parece haber sido suficiente para garantizar la presencia en la oferta mediático-cultural del 


\section{DISERTACIONES}

ENSAYOS

Estudios de audiencias y recepción: audiencias minoritarias y nuevas mediaciones

ISSN: 1856-9536

Doi: http://dx.doi.org/10.12804/revistas.urosario.edu.co/disertaciones/v11i1

Volumen 11, Número 1 / Enero-junio 2018

Versión PDF para imprimir desde

http://revistas.urosario.edu.co/index.php/disertaciones

pluralismo y la diversidad prometidos. Si nos fijamos en la oferta mediática en España, vemos cómo los grupos minoritarios apenas tienen cabida en los medios generalistas o en los especializados/temáticos. El único rastro que parece responder en cierto modo a aquella idea de "democratización de la información" son los diversos espacios televisivos especializados en una creencia religiosa, que también merecen cierta crítica -0 , al menos, una reflexión-, pues ¿hasta qué punto estos programas estanco no hacen sino fortalecer la diferencia (señalando a un "otros" frente a un "nosotros") en lugar de consolidar la hibridación en aras de mejorar la convivencia interreligiosa? Una pregunta ineludible, más si tenemos en cuenta la expansión de la islamofobia a partir de los atentados del 11 de septiembre, basada en el desconocimiento y la explotación de los discursos de odio y miedo (Bayrakli \& Hafez, 2015).

Ante esta escasa dedicación que han recibido las minorías en el ámbito del estudio de las audiencias, este texto se propone reunir ideas y conceptos esenciales con el fin de contribuir a reconducir esta tendencia. Empezaremos definiendo qué entendemos por minorías y a continuación abordaremos brevemente los condicionantes que se derivan del entorno global digital de cara a la ampliación de la visibilidad de las mismas. Los siguientes apartados se centrarán en el estudio de un colectivo específico: el de las migraciones. En primer lugar, se apuntarán las nociones teóricas que se han venido consolidando: transnacionalidad e interseccionalidad, en detrimento del pensamiento colonial. Para acabar se ofrecerá una panorámica de los principales objetos de estudio abordados. No es casualidad que los tres estudios indicados en el primer párrafo de esta introducción se refieran a minorías étnicas y/o ligadas a procesos migratorios, pues lo cierto es que estas suponen una de las excepciones en esa carencia detectada (Huertas, 2005; Browne, 2005). Además, desde el año 2007, la autora de este texto dirige la línea de trabajo "Comunicación, Migración y Ciudadanía” en el Institut de la Comunicació de la Universitat Autònoma de Barcelona (InCom-UAB) y, a partir de nuestra experiencia investigadora, nos proponemos recoger aquí las cuestiones teóricas y metodológicas básicas, especialmente aquellas que proceden de un fuerte proceso de autocrítica por parte de la comunidad investigadora. No trataremos, por tanto, de explicar el comportamiento de la población migrante como audiencia, tarea que sería inabarcable en un texto de estas dimensiones - dada la enorme diversidad interna- y nos desviaría de la principal finalidad que no es otra que recoger las zapatas teóricas y metodológicas de las que ya se dispone para el desarrollo de una sólida investigación sobre las minorías como públicos.

\section{La definición de la noción de minorías}

Appadurai (2006) habla de la ideología mayoritaria y, en el otro extremo, sitúa a las minorías, incluyendo a "los pobres, los desposeídos, los débiles y los marginados de nuestro mundo" (p. 9). Touraine (2005) es todavía más tajante y, a partir de unas reflexiones muy centradas en los movimientos sindicalistas y obreros, ubica a los precarios y excluidos "fuera de la escala, suspendidos en el vacío" (p. 26). Bhabha (2013) desdibuja todavía más el perfil y junto a los grupos de inmigrantes y de refugiados políticos incluye a las víctimas de cualquier forma de violencia. A partir de la revisión bibliográfica realizada, se desprende que las minorías son grupos sociales excluidos, tratados de forma desigual y, en mayor o menor grado, estigmatizada.

Pero la cuestión es mucho más compleja de lo que esta definición sugiere. De hecho, el propio vocablo "minoría" resulta bastante equívoco. En primer lugar, la palabra da a entender que solo hace referencia a grupos con reducida presencia en la sociedad y esta característica no siempre aparece. En una sociedad determinada puede 


\section{DISERTACIONES}

ENSAYOS

Estudios de audiencias y recepción: audiencias minoritarias y nuevas mediaciones

ISSN: 1856-9536

Doi: http://dx.doi.org/10.12804/revistas.urosario.edu.co/disertaciones/v11i1

Volumen 11, Número 1 / Enero-junio 2018

Versión PDF para imprimir desde

http://revistas.urosario.edu.co/index.php/disertaciones

haber grupos numéricamente mayoritarios tratados en calidad de minoritarios y al mismo tiempo grupos minoritarios por su volumen pueden disponer de una visibilidad cercana a la de los colectivos mayoritarios. Si nos centramos en el caso español, podemos utilizar los datos del Instituto Nacional de Estadística (INE), que cifra la población total del país a 1 de enero de 2016 en 46445828 habitantes, para explicar con referencias concretas lo que acabamos de enunciar.

Sobre la primera cuestión, el INE señala que el $49,1 \%$ de la población española son hombres y que el 50,9\% son mujeres, es decir, la proporción de mujeres es mayor que la de hombres en el conjunto de la sociedad, mientras que su presencia en determinados espacios tiene un perfil minoritario. Por ejemplo, en el ámbito académico, tan solo el $20,6 \%$ de las cátedras están ocupadas por mujeres. Vayamos ahora al segundo planteamiento, las minorías que no son tratadas como tales, y, para ello, hablaremos de la juventud, definiéndola como la población comprendida entre los 20 y los 34 años a partir también de las estadísticas que ofrece el INE. Este grupo social asciende a unos 9 millones y medio de personas, supone por tanto aproximadamente un $20 \%$ de la población total española $y$, de hecho, el propio INE en sus documentos muestra su preocupación por la elevada tasa de envejecimiento del país y el decrecimiento de los nacimientos. Sin embargo, por efecto del elevado valor que hoy en día se concede a la juventud, hecho que al mismo tiempo desdibuja las edades que comprenden este periodo biológico y vital, gran parte de la oferta mediática-cultural está dirigida casi exclusivamente a este segmento social (Pogue, 2014).

En segundo lugar, hablar de minorías parece dirigirnos inequívocamente a grupos estigmatizados y esto tampoco resulta siempre así. Hay grupos que, aun minoritarios en cuanto a su tamaño, disponen de elevado poder, es decir, ser un colectivo de volumen reducido no siempre es sinónimo de exclusión social. Podemos mencionar aquí las élites económicas con sus respectivos grupos de presión (lobbies) o indicar lo inadecuado que sería aplicar la noción de gueto a una urbanización de lujo, pues su situación marginal no es equiparable a lo que se entiende por periferias urbanas, sobre las cuales también cabe advertir que tampoco están situadas exclusivamente en las afueras de las grandes ciudades.

Hechas estas aclaraciones, llegamos a la conclusión de que lo que realmente caracteriza a las minorías es el no disponer de canales para autoreferenciarse ni para hacer presión. Las minorías son grupos oprimidos (quienes ostentan el poder abusan de ellos), "sin voz" o "mudos" (otros hablan por ellos) y "sin agencia" (otros deciden por ellos). En consecuencia - y esta es otra característica- pertenecer a una minoría siempre supone vivir una experiencia traumática.

Para entender esta definición, cabe recordar además que las minorías son una categoría social y demográfica reciente, generada por las nuevas preocupaciones relativas a derechos humanos, ciudadanía, pertenencia y autoctonía. En palabras de Appadurai (2006):

Las minorías y las mayorías emergen explícitamente en el proceso de desarrollo de las ideas de número, representación y derecho al voto en las zonas donde se llevaron a cabo las revoluciones demográficas del

siglo xvII, incluyendo las regiones satélites del mundo colonial (p. 59).

Su gestación ha promovido, además de nuevas obligaciones a los Estados, el crecimiento de determinados movimientos sociales que, en palabras de Touraine (2005) "no buscan integrarse en la sociedad, sino mantener la distancia que separa al sujeto y sus derechos de la maquinaria social y sus mecanismos de autocontrol" (p. 152). Pero después vino el pesimismo, explicado así por Touraine (2005) y en el que el mismo pensador se encuentra inmerso: 


\section{DISERTACIONES}

ENSAYOS

Estudios de audiencias y recepción: audiencias minoritarias y nuevas mediaciones

ISSN: 1856-9536

Doi: http://dx.doi.org/10.12804/revistas.urosario.edu.co/disertaciones/v11i1

Volumen 11, Número 1 / Enero-junio 2018

Versión PDF para imprimir desde

http://revistas.urosario.edu.co/index.php/disertaciones

cierto es que los nuevos movimientos sociales que aparecieron después de 1968 se agotaron rápidamente, y que las esperanzas puestas en ellos por diferentes categorías de intelectuales, y en primer lugar por mi mismo, se vieron frustradas. Los núcleos de extrema izquierda, si bien ofrecen una expresión política a aquellos que no se reconocen ya en los partidos tradicionales, no pueden proponer ni una estrategia a largo plazo ni unos objetivos de lucha (p. 27).

\section{Las dimensiones de la globalización: minorías digitales}

Una de las principales necesidades de las minorías es poder "visibilizar su derecho a narrar y a dar testimonio de la experiencia traumática que constituye su minoridad" (Bhabha, 2013, p. 13). Al centrar este ensayo en la comunicación, este enfoque nos interesa especialmente. Aunque mi interés personal va mucho más allá -comprobar si finalmente les es posible hacer sombra al discurso dominante (mainstream) o si solo alcanzan a poner en circulación esa mirada propia y alternativa-, resulta todavía muy precipitado intentar responder a la pregunta sobre si el entorno digital permite realmente una expansión de esas visibilidades reducidas. ¿Qué resultados alcanza el ciberactivismo?, ¿qué elementos interfieren en su eficacia?, ¿las minorías se podrán acabar convirtiendo en "minorías inteligentes"?, adaptando la terminología empleada por Rheingold (2004).

Con este punto de partida, dos preocupaciones nos asaltan y ambas generan nuevas líneas de trabajo. Primero, dadas las dimensiones culturales de la globalización, ¿qué grado de presión pueden acabar ejerciendo los grupos minoritarios? Segundo, dada la importancia que ha adquirido en la sociedad actual la necesidad de dar visibilidad a nuestra identidad, ¿hasta qué punto los movimientos sociales ligados a minorías no corren el riesgo de diluirse como tales, y terminar absorbidos por esa obligación?

Mucho se ha hablado ya de lo que supone la sociedad de la información en términos de desterritorialización y también en relación a la cultura (Sierra-Caballero, 2016). Las posibilidades de conexión y de cocreatividad social se han multiplicado:

vivimos en una época en que las conexiones transnacionales son cada vez más variadas y penetrantes, con mayores o menores consecuencias para la vida humana y para la cultura (...). La tecnología de la movilidad ha cambiado y los medios de comunicación, cada vez más variados, nos llegan desde allende las fronteras reclamando la atención de nuestros sentidos. No nos resulta difícil imaginar lo que se encuentra a grandes distancias. Al contrario, nuestra imaginación se alimenta a menudo de la distancia y de las muchas formas en que lo distante puede convertirse de pronto en próximo (Hannerz, 1998, p. 17).

Pero ahora toca pensar sobre cómo la sociedad gestiona los nuevos recursos comunicativos y, en este texto, focalizamos la atención en la necesidad de estudiar cómo las minorías las emplean para mostrar sus propias narrativas y, en consecuencia, para su movilización. Aunque no nos situamos ni en el extremo netópico -internet como utopía - ni en el distópico - negación de la efectividad política de la acción en la red- (Reverter-Bañon, 2006), creemos que es urgente abordar la cuestión tanto a partir de la reflexión teórica como del trabajo empírico. Eso sí, sin olvidar que la comunicación alternativa es un terreno que tiene ya una amplia historia.

El ciberactivismo no es una disrupción en la evolución de la sociedad de la información. Los fanzines, los carteles, los murales, las radios libres, el Rock... pueden ser considerados los antecedentes de los blogs, los memes, los grafitis, los canales de youtube, el hip-hop... La construcción de espacios simbólicos y comunicativos propios, 


\section{DISERTACIONES}

ENSAYOS

Estudios de audiencias y recepción: audiencias minoritarias y nuevas mediaciones

ISSN: 1856-9536

Doi: http://dx.doi.org/10.12804/revistas.urosario.edu.co/disertaciones/v11i1

Volumen 11, Número 1 / Enero-junio 2018

Versión PDF para imprimir desde

http://revistas.urosario.edu.co/index.php/disertaciones

al margen de la lógica del beneficio, no es algo novedoso. Además, tampoco dudamos de la necesidad de seguir insistiendo en la idea de que la tecnología no es neutra:

Es preciso que nos preguntemos por qué una determinada razón técnica se consideró ineludible cuando podía haberse cuestionado, y qué es lo que determina su superioridad técnica en circunstancias específicas. Los estudios ponen de manifiesto que la generación y la aplicación de nuevas tecnologías supone tener muchas opciones técnicas. Una serie de factores sociales afecta a qué opciones técnicas serán seleccionadas. Estas opciones conforman las tecnologías y, por consiguiente, las implicaciones sociales de las mismas. De esta manera, la tecnología es un producto sociotécnico, conformado por las condiciones de su uso y creación (Wajcman, 2006, pp. 55-56).

Sobre la identidad, después de que la cultura mediática haya inculcado que todo individuo no solo ha de encontrar elementos con los que identificarse sino que también lo ha de hacer visible (Kellner, 2011; Huertas-Bailén, 2015; Mafessoli, 2007), el entorno digital genera nuevas preocupaciones. Touraine (2005) lo expresa claramente cuando apunta que la obsesión por la identidad puede acabar desdibujando el sentido de la lucha de las minorías, pues este puede quedar subsumido totalmente en la cuestión de la visibilidad. Además, a esa preocupación por construir una identidad digital se le suma ahora el temor de los posibles efectos negativos de su permanencia en el tiempo al quedar registrada en las redes sociales (Boyd, 2008). Estamos hablando de la memoria colectiva que queda almacenada, asunto de enorme importancia para las minorías. Recogemos, a continuación, una cita en la que se señalan de forma clara las responsabilidades que supone en este sentido el uso de las tecnologías digitales (TD).

las visualidades como 'modos de constituir la producción del sentido y la subjetividad' tienen un papel cada vez más predominante en la forma de representar y ejercer la ciudadanía. El potencial de las TD para facilitar y fomentar el uso, la producción, el almacenamiento, la transmisión, el intercambio, la reapropiación, la remezcla, la reutilización de imágenes, implican la necesidad de profundizar nuestra conciencia tanto sobre el efecto que nos producen como el que nosotros podemos llegar a producir (Sancho, Hernández \& Rivera, 2016, p. 29).

Aquella "democratización de la información" ya no debe entenderse únicamente como la garantía de un acceso universal a una oferta mediática plural, sino que también ha de incorporar el interés por potenciar la participación y la creación. Tal vez el empoderamiento que las tecnologías digitales puede suponer para las minorías $-\mathrm{y}$, sobre todo, la posibilidad de que el sistema de comunicación pretendidamente inclusivo se sienta resquebrajado- sirva como detonante del estudio de las "minorías digitales". Las nuevas formas de colectividad que ofrece el entorno digital o, en palabras de Sierra-Caballero (2016), los "nuevos procesos de desarrollo cultural del ser y sentido de la ciudadanía" (p. 60) quizá nos lleven a la necesidad de indagar sobre el comportamiento mediático de las minorías; aunque lo cierto es que también tenemos serias dudas sobre la capacidad de los medios digitales como emancipadores frente al discurso hegemónico y potenciadores de una mayor flexibilidad en el espacio público.

No queremos desarrollar aquí esta discusión, ya que ello implicaría entrar de lleno en cuestiones ideológicas -y tampoco es este un lugar apropiado para elaborar un ensayo completo sobre el tema-, pero sí consideramos preciso apuntar que nos resulta extremadamente llamativo observar hechos como el siguiente, por el paradójico contraste que supone. En la Unión Europea, además de que el nivel de desigualdad varía de un país a otro, para evitar la discriminación en el acceso a servicios y bienes, tan solo existe una ley y esta hace referencia a la raza, es decir, 


\section{DISERTACIONES}

ENSAYOS

Estudios de audiencias y recepción: audiencias minoritarias y nuevas mediaciones

ISSN: 1856-9536

Doi: http://dx.doi.org/10.12804/revistas.urosario.edu.co/disertaciones/v11i1

Volumen 11, Número 1 / Enero-junio 2018

Versión PDF para imprimir desde

http://revistas.urosario.edu.co/index.php/disertaciones

no existe ninguna ley que trate sobre la orientación sexual u otros motivos que puedan provocar discriminaciones, según explicó Ulrike Lunacek, vicepresidenta del Parlamento Europeo y copresidenta del intergrupo por los Derechos LGTB, en una entrevista publicada en el Diario de Mallorca el 29 de diciembre de 2016 y firmada por Mar Ferragut. En este contexto, ¿podrá convertirse el entorno digital realmente en un espacio para la igualdad? Es utópico pensar que lo on-line pueda ir en dirección contraria (ni tan solo diferente) a lo off-line.

Además, tampoco sería correcto eludir la posibilidad de que esas minorías acaben adquiriendo un tono esencialista (Leung, 2007; Barker, 2003) e incluso fundamentalista. Desde Europa, podemos citar, por ejemplo, al grupo católico de extrema derecha Alliance Générale Contre le Racisme et pour le respect de l'Identité Française et Chrétienne (AGRIF), cuyo perfil en Facebook tiene en enero de 2017 más de 4000 seguidores. Esta agrupación siempre reacciona de forma muy activa ante publicaciones críticas con el cristianismo; por ejemplo, son habituales sus inmediatas respuestas a las publicaciones del diario satírico francés Charlie Hebdo.

\section{El estudio sobre la población migrante}

\section{Perspectivas teóricas y metodológicas: transnacionalismo e interseccionalidad}

Dentro de los límites que supone la ausencia (e imposibilidad) de una teoría global de las migraciones, la perspectiva transnacionalista ha logrado imponerse (Cloquell \& Lacomba, 2016). Las críticas que sistemáticamente recibió el denominado "nacionalismo metodológico" por parte de muchos autores, entre los que podemos destacar a Will Kymlicka (1996), tuvieron finalmente efecto. El nacionalismo metodológico implicaba utilizar categorías de análisis fijadas en función del país de nacimiento/raíces culturales, lo que acababa no solo reforzando los estereotipos nacionales, sino también eludiendo dar cuenta de los hoy inevitables procesos de hibridación cultural transnacional. A nuestro modo de ver, las miradas teóricas más acertadas se desprenden de la fusión de los estudios poscoloniales de la antropología con el transnacionalismo (Appadurai, 2006; Hannerz, 1998; Bhabha, 2013). Una opción la encontramos en el trabajo de Linda Leung (2007), quien ya describió la internet de la década de los noventa del siglo xx como un espacio solo para la población blanca y masculina.

En un mundo globalizado, donde se ha incrementado el desplazamiento de mensajes y personas (Morley, 2005), la vida del migrante ya no queda circunscrita al país (o frontera territorial-política-cultural) donde instala su nueva residencia, pero tampoco queda supeditada de forma exclusiva al mantenimiento de sus raíces culturales. Si nos centramos en la comunicación, esta transnacionalidad resulta evidente, queda reflejada claramente en el papel que ejercen los medios a la hora de generar imaginarios que impulsan a emigrar, como apunta Lucía Benítez-Eyzaguirre (2013) en su estudio sobre cómo la imagen idílica de Europa es determinante a la hora de decidir emigrar para la población del norte de África, y en todas las investigaciones sobre la comunicación interpersonal, pues esta se produce con familiares y amistades residentes en diferentes países. Esta imposición del transnacionalismo en el estudio de las migraciones es precisamente lo que ha provocado la consolidación del uso del término migrante, anulando los vocablos emigrante, que remarca el proceso de salida, e inmigrante, que remarca el proceso de llegada.

Sin embargo, todavía queda por resolver la siguiente pregunta: ¿en qué momento la población migrante puede dejar de ser considerada como tal? Es más, junto a los compartimentos estancos habituales, como "pri- 


\section{DISERTACIONES}

ENSAYOS

Estudios de audiencias y recepción: audiencias minoritarias y nuevas mediaciones

ISSN: 1856-9536

Doi: http://dx.doi.org/10.12804/revistas.urosario.edu.co/disertaciones/v11i1

Volumen 11, Número 1 / Enero-junio 2018

Versión PDF para imprimir desde

http://revistas.urosario.edu.co/index.php/disertaciones

mera generación" o "segunda generación", ahora también empieza a hablarse de la "generación cero". Se trata de los progenitores que emigran para pasar su vejez en los países donde sus hijos/as emigraron previamente, un fenómeno que, en el caso español, comienza a ser relevante entre la comunidad china y que está produciendo un nuevo tipo de aislamiento social (Kniffki \& Reutlinger, 2016). Kymlicka (1996) marca como punto de inflexión en el proceso de adaptación a la tercera generación, ya que considera que es aquí cuando la lengua del país de acogida se convierte en la lengua materna y cuando el aprendizaje de la lengua de origen es como el de cualquier otra lengua extranjera, pero la cuestión es si esto sigue teniendo sentido en un mundo hiperconectado como el actual. Además de que esta afirmación no resulta útil para explicar procesos migratorios donde no es necesario el aprendizaje de otra lengua para el proceso de adaptación, tampoco parece tener en cuenta lo que supone la globalización en cuanto al conocimiento y acercamiento a otras lenguas.

En comparación con el proceso de implantación de la teoría de la transnacionalidad, la consolidación de la interseccionalidad no está teniendo un camino tan fácil y, de hecho, todavía le falta superar muchos obstáculos. Kimberlé Crenshaw presentó este concepto en la Conferencia Mundial contra el Racismo en Sudáfrica en 2001 (Expósito-Molina, 2012). Crenshaw (1995) planteó que había categorías como la raza y el género que interseccionaban e influían en la vida de las personas (el racismo no tiene los mismos efectos entre hombres y mujeres negras, ni tampoco las mujeres negras viven el sexismo como las mujeres blancas); por tanto es imprescindible trabajar teniendo siempre en perspectiva la intersección entre etnia/raza, género, clase social y experiencia migratoria. Quizá el hecho de que el término se haya formulado desde el feminismo sea lo que está dificultando la expansión de su uso, aunque también hay que considerar la dificultad que supone su aprehensión metodológica. ¿Cómo transformar la interseccionalidad en variables de análisis asumibles en un trabajo empírico?

De alguna manera, la suma de estas dos perspectivas (transnacionalismo postcolonial e interseccionalidad) es lo que permite huir del pensamiento dicotómico jerárquico, para alejarnos así tanto de la visión enfrentada (norte/sur) como de la endogámica (norte y sur se autodefienden, dando como resultado miradas eurocéntricas y latinocéntricas), que no favorecen el desarrollo de nuevas ideas. No obstante, todavía es posible encontrar estudios sobre la interculturalidad que, al no haber abandonado la mirada colonial, apuntan a la confrontación entre "espacios tempoculturales", como si la migración provocara la coincidencia en una misma ciudad de colectivos que andan a destiempo en el decurso de la historia. ¿Acaso la historia puede explicarse de forma lineal? Hace ya muchos años que Hans Magnus Enzensberger (1999) defendió la asincronía y rechazó el pensamiento sobre una temporalidad lineal o que Wolf (1994) apuntó que la historia social se ha de explicar a través de "coexistencias" y no de "ciclos". Recordemos también las "oscilaciones pendulantes" de Langer (2000).

David Morley (2005), desde Europa, lo expone de forma clara cuando señala que aunque se perciba como positivo el nacimiento de nuevos y ricos "espacios tempoculturales", en Occidente es común caer en un discurso que habla del "otro" como pasado/subdesarrollo frente a un "nosotros" ligado al progreso/desarrollo. Y, todavía con más contundencia, se expresa la socióloga turca Nilufer Göle (2007):

en el contexto europeo, en el que se ha perdido la comodidad de la distancia y se han sincronizado las prácticas, la cuestión de la proximidad surge con fuerza. Más que en cualquier otra región del mundo, es en Europa donde la tensión entre contemporaneidad e islam se plantea como una cuestión crucial, de la que depende el futuro europeo, ya que es en Europa donde este encuentro conflictivo se manifiesta como proximidad del uno con el otro (p. 14). 


\section{DISERTACIONES}

ENSAYOS

Estudios de audiencias y recepción: audiencias minoritarias y nuevas mediaciones

ISSN: 1856-9536

Doi: http://dx.doi.org/10.12804/revistas.urosario.edu.co/disertaciones/v11i1

Volumen 11, Número 1 / Enero-junio 2018

Versión PDF para imprimir desde

http://revistas.urosario.edu.co/index.php/disertaciones

\section{El estudio del consumo mediáticocultural}

La oferta mediáticocultural está formada por bienes y servicios a los que el conjunto de la ciudadanía debe poder acceder, entendiendo este acceso en el sentido más amplio, ya que incluye participación y creación. Los estudios culturales ya ahondaron en la importancia de estos bienes y servicios, atendiéndolos no solo como fuente de recursos socioculturales sino también como una vía para la participación ciudadana (Curran, Morley \& Walkerdine, 1998). Es decir, seguimos la línea marcada por Mata (2006) con la noción de "ciudadanía comunicativa", pero avanzando con Couldry, Livingstone y Markham (2007) hacia la "conexión pública" (public engagement).

Con esta perspectiva, y en coherencia con el transnacionalismo poscolonial, para el estudio del consumo cultural ya no resulta útil la clásica tipología que distinguía entre integración, segregación y asimilación a la hora de hablar de la experiencia migratoria en el país de acogida. La urgencia de huir de visiones racistas y paternalistas, unida a la consideración de la necesidad de un acceso pleno a la oferta mediáticocultural para el conjunto de la ciudadanía, supone enfrentarnos con el estudio de la hibridación, del cosmopolitismo. Ahora bien, tampoco se trata de adoptar una mirada ingenua. Conviene tener presentes los problemas planteados por Morley (2005). Este autor, por un lado, apunta que los contenidos generados en la cultura occidental suelen enfocarse en una visión eurocentrista y, por otro lado, que la población migrante, al igual que tiende a segregarse en el espacio urbano, es posible que sea propensa a concentrar su consumo mediático en contenidos afines a sus raíces culturales. Lo cierto es que el trabajo propio en el InCom-UAв apunta a que el consumo mediático tiende a la diversidad y, en caso de darse rechazo hacia contenidos elaborados desde la cultura del nuevo país de residencia, este se concentra ante determinados contenidos y en perfiles sociodemográficos específicos. Por ejemplo, las informaciones que asocian de forma acrítica islam y terrorismo generan una fuerte oposición entre la población musulmana (migrante y no migrante), o la población que desconoce las lenguas del nuevo entorno de convivencia también tiende a concentrar el consumo mediático -sobre todo, de ficción - en productos en versión original procedentes de sus países de origen. En el caso español, esto último lo hemos encontrado de forma muy marcada entre la población procedente de Europa del este.

Al analizar el consumo mediático desde la perspectiva de los públicos formados por población migrante, resulta muy útil clasificar la oferta disponible en función de la zona geográfica y cultural de origen. A partir de este criterio, tenemos contenidos:

a) Dirigidos a la población inmigrada. Aquí se incluyen i) los “medios étnicos", pensados de forma exclusiva para la población inmigrada, producidos mayoritariamente en el nuevo país de residencia (Gómez-Escalonilla, 2008); ii) los medios diaspóricos, dirigidos a lo que Tölölyan (2012) denomina "comunidades en dispersión" entre diferentes países, que pueden estar gestionados desde los gobiernos de los países emisores -como hace China (Nieto, 2007) - o por la propia población migrante, y iii) los medios que, aunque están dirigidos a la población que permanece en la zona geográfica de nacimiento, son fácilmente accesibles desde otros países gracias a las tecnologías digitales.

b) Dirigidos a la población autóctona. Estos están enfocados principalmente a la población autóctona del eufemísticamente llamado país de acogida, aunque (en versión original o no) también pueden incluir oferta procedente del país de nacimiento de la población inmigrada. Es lo que sucede, por ejemplo, desde la perspectiva del colectivo latinoamericano en España con las telenovelas. 


\section{DISERTACIONES}

ENSAYOS

Estudios de audiencias y recepción: audiencias minoritarias y nuevas mediaciones

ISSN: 1856-9536

Doi: http://dx.doi.org/10.12804/revistas.urosario.edu.co/disertaciones/v11i1

Volumen 11, Número 1 / Enero-junio 2018

Versión PDF para imprimir desde

http://revistas.urosario.edu.co/index.php/disertaciones

c) Dirigidos al conjunto de la ciudadanía por responder a una cultura global. Nos referimos aquí al mercado mundial formado por los grandes conglomerados empresariales del sector del entretenimiento y de la creación (Martel, 2012), ámbito en el que se producen fuertes luchas geopolíticas culturales (soft power).

Es decir, se contempla la cultura que la persona hereda de su entorno sociofamiliar (raíces culturales, étnicas, raciales), la que se encuadra en el nuevo espacio de convivencia (urbana, local, comunitaria, nacional) y la de alcance global. Sin embargo, aunque resulta bastante sencillo acotar conceptualmente estos tres ámbitos, los límites pueden ser algo más difusos cuando nos adentramos en lo empírico debido al modo como funciona el mercado de los productos culturales. Una buena prueba para mostrar esta cuestión la encontramos en la afrobrasileña capoeira: un producto local (monocultural) que se ha convertido en transnacional (multicultural) sin perder los elementos que la identifican con sus raíces culturales (Wulfhorst \& Vianna, 2012). La capoeira mezcla danza, artes marciales y música, y en noviembre de 2014 fue declarada Patrimonio Cultural Inmaterial de la Humanidad por la Unesco (Organización de las Naciones Unidas para la Educación, la Ciencia y la Cultura). Esta amplia visión de la oferta cultural lleva a pensar la identidad cultural como algo flexible: las señas de identidad son elaboradas y reelaboradas continuamente por los individuos y, en el caso de la población migrante, este proceso es, si cabe, todavía más evidente. Serrano-Niza (2011) emplea el concepto de "individuo frontera", en un intento por recoger así las múltiples combinaciones y mezclas culturales que pueden generarse en la experiencia migratoria.

Los estudios existentes sobre el consumo cultural de la población migrante son mayoritariamente de carácter cualitativo. Como pioneras de esta línea de trabajo podemos mencionar a Marie Gillespie (1995), concretamente sus estudios empíricos sobre el consumo mediático y los estilos de vida de las familias hindúes en Londres, y a Ana Uribe (2004), quien trabaja sobre el seguimiento de las telenovelas por parte de mexicanos en el exterior. En el contexto español, cabe mencionar diversos trabajos, principalmente sobre la población latinoamericana (Retis, 2011; Díaz Nosty, 2006; Cogo, Gutiérrez \& Huertas, 2008) y sobre la población musulmana migrante (Huertas, Martínez \& Moreras, 2013).

Aunque la mayor parte de las aportaciones proceden del ámbito académico, también existen indicios que demuestran el interés comercial por conocer los hábitos comunicativos de esta población. Así, en España, el Estudio General de Medios (EGM) de la Asociación para la Investigación de la Comunicación de Masas (AIMc) introdujo en el 2002 una pregunta encaminada a registrar la nacionalidad del entrevistado o, en el contexto catalán, el hoy desaparecido Barómetro de la Comunicación y la Cultura - responsabilidad de la fundAcc (Fundació Audiències de la Comunicació i la Cultura) y activo entre 2007 y 2015-incluyó en su muestra a la población extranjera. Es más, llegaron a difundirse estudios de mercado especializados en este grupo social; nos referimos al Emı (Estudio de Medios para Inmigrantes), un proyecto de la ACPI (Asociación para el Conocimiento de la Población Inmigrante) del que solo se realizaron dos ediciones, en los años 2007 y 2008.

En cambio, el ámbito de la recepción apenas se ha desarrollado. Este enfoque parece concentrarse en dos áreas. Por un lado, la percepción que la comunidad migrante tiene del modo en que los medios de comunicación la representan (Tortajada, 2009; Cogo, Gutiérrez \& Huertas, 2008) y, por otro, el potencial de los medios a la hora de modificar la actitud de los autóctonos hacia los "otros" (Igartua \& Frutos, 2016). Esto último también se viene explorando desde hace tiempo a partir de la relación entre educación mediática e interculturalidad, ámbito en el que es habitual el testeo de las posibilidades de la denominada investigación acción (Huertas-Bailén \& Martínez-Suárez, 2013a).

\section{0}




\section{DISERTACIONES}

ENSAYOS

Estudios de audiencias y recepción: audiencias minoritarias y nuevas mediaciones

ISSN: 1856-9536

Doi: http://dx.doi.org/10.12804/revistas.urosario.edu.co/disertaciones/v11i1

Volumen 11, Número 1 / Enero-junio 2018

Versión PDF para imprimir desde

http://revistas.urosario.edu.co/index.php/disertaciones

\section{El estudio del uso de las tecnologías digitales}

Al menos de momento, en lo relacionado al uso de las tic por parte de la población migrante, la mayor parte de los trabajos disponibles se centran en la comunicación interpersonal transnacional. El análisis de las redes sociales que rodean todo proceso migratorio ha sido siempre un objeto de estudio habitual (Zanfrini, 2007) y, por tanto, esta tendencia es plenamente coherente con los estudios previos desde la sociología de las migraciones.

Uno de los primeros estudios que alertaron sobre el cambio que supondrían las tic en la comunicación intrafamiliar es el de los antropólogos Miller y Slater (2000), quienes estudiaron el uso de herramientas textuales por parte de la población de la isla de Trinidad para mantener el contacto con familiares emigrados. Pero la evolución tecnológica ha ido más allá al romper las limitaciones espacio-temporales y al expandirse la posibilidad de compartir imágenes (fijas y en movimiento) se ha necesitado crear términos específicos para hablar de estas nuevas experiencias comunicativas. Uno de los más interesantes es la noción de "presencia conectada" propuesto por Licoppe (2004) para referirse a la comunicación interpersonal en la que se comparte el tiempo a pesar de la distancia.

El hecho de que los roles tradicionales estén fuertemente marcados por los núcleos familiares hace que la perspectiva de género sea prácticamente ineludible en estos trabajos. En un estudio empírico sobre familias colombianas transnacionales, Puyana, Motoa y Viviel (2008) alertaron de la centralidad de la figura de la madre: tanto en destino como en origen, las madres son una figura recurrente, un referente de consulta y también de apoyo. Sobre los temas de las conversaciones, los estudios disponibles, como el de de la Fuente (2011) sobre una muestra de cuarenta mujeres inmigradas en Barcelona, apuntan a que la fidelidad en la pareja y la educación de los hijos provocan una fuerte controversia. En un trabajo sobre las familias migrantes procedentes del Magreb en España, detectamos casos en los que el consumo mediático de las mujeres estaba fuertemente condicionado por el consumo familiar -la conexión a internet se evita desde el hogar, para proteger a niños/as de contenidos inadecuados, y eso reduce el acceso a la red por parte de las mujeres - o por las indicaciones de los varones adultos - se registraron casos en los que las mujeres indicaron que solo consumían películas que maridos/hermanos habían seleccionado especialmente para ellas- (Huertas-Bailén \& Martínez-Suárez, 2013b).

La creación en internet de espacios creados por y/o para comunidades migrantes específicas ha generado otro interesante objeto de estudio, aunque este ha sido menos explorado. En el ámbito teórico existe una fuerte discusión sobre la pertinencia del uso del término "diáspora" como genérico para hablar de las migraciones, pues estas no siempre responden a la definición ortodoxa que señala a una comunidad expulsada de su territorio original. Además, en el entorno digital, es habitual la autodenomiación "diáspora”, lo que genera la duda de si desde la investigación académica se ha de aceptar ese vocablo sin ningún tipo de discusión o reflexión previas. Tölölyan (2012) da una solución al problema y plantea el término de "comunidades en dispersión", intentando buscar un vocablo que recoja la variedad interna de este tipo de desplazamientos.

En este ámbito, de entre los estudios desarrollados, destacan por su excepcionalidad varios proyectos. Es obligatorio mencionar a Myria Georgiou (2006) y su trabajo sobre identidad y diásporas, así como la iniciativa digital de Dana Diminescu, e-Diasporas Atlas, que tiene como objetivo dar visibilidad en la red a la circulación que genera cada comunidad fuera de su país. El análisis de las conexiones y nudos permite ver los niveles de centralidad/dispersión de las mismas, lo que se puede observar en la dirección web del proyecto: http://www.e-diasporas.fr/index.html\#top 


\section{DISERTACIONES}

ENSAYOS

Estudios de audiencias y recepción: audiencias minoritarias y nuevas mediaciones

ISSN: 1856-9536

Doi: http://dx.doi.org/10.12804/revistas.urosario.edu.co/disertaciones/v11i1

Volumen 11, Número 1 / Enero-junio 2018

Versión PDF para imprimir desde

http://revistas.urosario.edu.co/index.php/disertaciones

Otra manera de observar este contenido es el de Claire Scopsi (2009), quien analiza la memoria colectiva que se acaba construyendo en el espacio digital a partir básicamente de las webs creadas por cada comunidad.

\section{A modo de cierre: la lucha contra el mediacentrismo}

A los medios de comunicación tradicionales ahora se une la actividad ciudadana con la ampliación del uso de las tecnologías digitales, de manera que el control sobre los espacios comunicativos de poder resulta mucho más complejo. A un sistema de comunicación supuestamente inclusivo, se suman ahora unas minorías empoderadas por el acceso a nuevas herramientas comunicativas. Este es el escenario, pero ¿hasta qué punto el ciberactivismo es capaz de alterar el status quo? Esta es la pregunta de la que partimos y, en aras de ir construyendo posibles respuestas, hemos elaborado este escrito. Pero, llegados al cierre, todavía nos queda por enunciar una cuestión central más: la necesidad de revisar de manera crítica el mediacentrismo que históricamente padece el estudio de las audiencias.

Provocar este giro no va a ser sencillo. Por un lado, en el ámbito académico parece escasear esta preocupación, una prueba la encontramos en el uso extendido de conceptos binomio que responden a visiones enfrentadas con la tecnología en un lugar central (tecnofobia/tecnofilia), como si fuera posible aislar lo técnico de lo social, lo político, lo cultural... Por otro lado, la comunicación está ocupando un papel central en muchas de las interpretaciones de las realidades que nos envuelven. Recuerden lo sucedido con las denominadas "primaveras árabes" y el papel clave que algunos autores concedieron a la TD en la formación de esos movimientos sociales, por sus posibilidades de convocatoria y difusión. O piensen también en las tendencias actuales en el ámbito legislativo concretamente en el cada vez hay mayor interés por regular qué es aceptable dentro de la noción de "libertad de expresión" en el marco de las redes sociales digitales.

Ante el tipo de objetos de estudio aquí planteados, una reflexión autocrítica sobre el mediacentrismo resulta ineludible, pues la desigualdad y la estigmatización social son resultado de un proceso que va mucho más allá de la comunicación. Por tanto, al reto de entender las posibilidades reales de actuación de las "minorías digitales" en un contexto más predispuesto a garantizar lo que responde a valores tradicionales y conservadores que a la flexibilidad del discurso público, hay que añadir una exigencia quizá todavía más difícil de asumir ya que trastoca los cimientos en los que se asientan gran parte de las teorías de la comunicación.

\section{Referencias}

1. Appadurai, A. (2006). El rechazo de las minorías. Ensayo sobre la geografía de la furia. Barcelona: Tusquets

2. Barker, C. (2003). Televisión, globalización e identidades culturales. Barcelona: Paidós.

3. Bayrakli, E., \& Hafez, F. (Comps.) (2015). European islamophobia report 2015. Estambul: SETA/Foundation for Political and Social Research.

4. Benítez-Eyzaguirre, L. (2013). La recepción transnacional de la televisión en los proyectos migratorios. Un estudio de caso en poblaciones marroquíes. Madrid: Editorial Círculo Rojo.

5. Bhabha, H. K. (2013). Nuevas minorías, nuevos derechos. Notas sobre cosmopolitanismos vernáculos. Buenos Aires: Siglo xxı Editores. 


\section{DISERTACIONES}

ENSAYOS

Estudios de audiencias y recepción: audiencias minoritarias y nuevas mediaciones

ISSN: 1856-9536

Doi: http://dx.doi.org/10.12804/revistas.urosario.edu.co/disertaciones/v11i1

Volumen 11, Número 1 / Enero-junio 2018

Versión PDF para imprimir desde

http://revistas.urosario.edu.co/index.php/disertaciones

6. Boyd, D. M. (2008). Taken out of context: Teen sociability in network publics (Tesis doctoral, Universidad de California, Berkeley: Estados Unidos). Recuperado de http://www.danah.org/papers/TakenOutOfContext.pdf

7. Browne, D. (2005). Ethnic minorities, electronic media, and the public sphere. Cresskill, Nueva Jersey: Hampton Press.

8. Castells, M. (1997). La era de la información, vol. 1: La sociedad red, vol. 2: El poder de la identidad, vol. 3: Fin de Milenio. Madrid: Alianza Editorial.

9. Cloquell Lozano, A., \& Lacomba Vázquez, J. (2016). El transnacionalismo revisitado: aportes y límites de una teoría de alcance intermedio para el estudio de las migraciones. Revista Española de Sociología (RES), 25(2), 227-240.

10. Cogo, D., Gutiérrez, M., \& Huertas, A. (2008). Migraciones transnacionales y medios de comunicación. Relatos desde Barcelona y Porto Alegre. Madrid: Los libros de la Catarata.

11. Couldry, N., Livingstone, S., \& Markham, T. (2007). media consumption and public engagement: Beyond the presumption of attention. Londres: Palgrave Macmillan.

12. Crenshaw, K. (1995). Mapping the margins: Intersectionality, identity, politics and violence against women of color. En K. Crenshaw, N. Cotanda, C. Peller \& K. Thomas (Eds.), Critical race theory. The key writings that formed the movement (pp. 357-383). Nueva York: The New Press.

13. Curran, J., Morley, D., \& Walkardine, V. (1998). Estudios culturales y comunicación. Barcelona: Paidós.

14. Díaz-Nosty, B. (2006). Los medios de comunicación en la experiencia migratoria latinoamericana (Informe). Madrid: Fundación Telefónica.

15. Expósito-Molina, C. (2012). ¿Qué es eso de la interseccionalidad? Aproximación al tratamiento de la diversidad desde la perspectiva de género en España. Investigaciones feministas, 3, 203-233.

16. Enzensberger, H.M. (1999). Zigzag. Barcelona: Anagrama.

17. Fajardo-Fernández, R., \& Soriano-Miras, R. M. (2016). La construcción mediática de la migración en el Mediterráneo: ¿no-ciudadanía en la prensa española? Revista Internacional de Estudios Migratorios, 6(1), 141-169.

18. Ferragut, M. (2916). Ulrike Lunacek: "Conozco a políticos que están dentro del armario, yo les animo a salir". Diario de Mallorca, 23.

19. de la Fuente, G. (2011). Les tic enmig de les relacions: tractament de la distància i la proximitat en les famílies transnacionals. Digithum, (13), 1420.

20. Georgiou, M. (2006). Diaspora, identity and the media: diasporic transnationalism and mediated spatialities. Cresskill, Nueva Jersey: Hampton Press.

21. Gillespie, M. (1995). Television, ethnicity and cultural change. Londres: Routledge.

22. Göle, N. (2007). Interpenetraciones. El islam y Europa. Barcelona: Ediciones Bellaterra.

23. Gómez-Escalonilla, G. (2008). Voces de la inmigración. Medios latinos en Madrid. Madrid: Editorial Universitas.

24. Hall, S., Hobson, D., Love, A., \& Willis, P. (1981). Culture, media, language. Londres: Hutchinson.

25. Hannerz, U. (1998). Conexiones transnacionales. Cultura, gente, lugares. Madrid: Edocopmes/Cátedra.

26. Huertas-Bailén, A. (2002). La audiencia investigada. Barcelona: Gedisa. 


\section{DISERTACIONES}

ENSAYOS

27. Huertas, A. (2005). El impacto de la migración internacional en el estudio de la audiencia de televisión. Logos. Midias, migraçoes e interculturalidades, 12,(edición especial), 51-60.

28. Huertas-Bailén, A. (2015). Yo soy audiencia: ciudadanía, público y mercado. Barcelona: Editorial voc.

29. Huertas-Bailén, A., \& Martínez-Suárez, Y. (2013a). La educación mediática como herramienta de integración social en contextos migratorios: estudio de casos a partir de mapeados de proyectos. En D. Aranda, A. Creus \& D. Sánchez-Navarro (Eds.) Educación, medios digitales y cultura de la participación (pp. 263-278). Barcelona: Editorial voc.

30. Huertas-Bailén, A., \& Martínez-Suárez, Y. (2013b). Maghrebí women in Spain: Family roles and media consumption. (oBs*) Observatorio (OberCom). Special Issue, 111-127.

31. Huertas, A., Martínez, Y., \& Moreras, J. (2013). Prácticas y consumos mediático-culturales del colectivo marroquí en España. Madrid: Observatorio Cultura y Comunicación/Fundación Alternativas.

32. Igartua, J. J., \& Frutos, F. J. (2016). Procesos de recepción y efectos socio-cognitivos de películas sobre inmigración. El papel moderador del prejuicio hacia inmigrantes. Migraciones, (40), 33-61.

33. Izquierdo Iranzo, P. (2014). Fisiognomía de la etnia y el género en el discurso publicitario. Anuario Electrónico en Estudios de Comunicación Social "Disertaciones", 7(2), 178-209.

34. Kellner, D. (2011). Cultura mediática. Estudios culturales, identidad y política entre lo moderno y lo posmoderno. Madrid: Editorial Akal.

35. Kniffki, J., \& Reutlinger, Ch. (2016). El trabajo social desde miradas transnacionales. Berlín: Frank \& Timme $\mathrm{GmbH}$.

36. Kymlicka, W. (1996). Ciudadanía multicultural. Barcelona: Paidós.

37. Langer, J. (2000). La televisión sensacionalista. El periodismo popular y las "otras miradas". Barcelona: Paidós.

38. Leung, L. (2007). Etnicidad virtual. Raza, resistencia y world wide web. Barcelona: Gedisa.

39. Licoppe, C. (2004). 'Connected' presence: the emergence of a new repertoire for managing social relationships in a changing communication technoscape. Environment and Planning D: Society and Space, 22(1), 135-156.

40. Lindlof, $T$ (1988). Media audiences as interpretative communities. Communication Yearbook, 11, 81-107.

41. Lipovetsky, G. (2000). La era del vacío. Ensayos sobre el individualismo contemporáneo. Barcelona: Anagrama.

42. Maffesoli, M. (2007). En el crisol de las apariencias. Para una ética de la estética. Madrid: Siglo xxı Editores.

43. Martel, F. (2012). Cultura mainstream. Madrid: Santillana.

44. Martín-Barbero, J. (1998). De los medios a las mediaciones. Bogotá: Convenio Andrés Bello.

45. Mata, M. C. (2006). Comunicación y ciudadanía: problemas teórico-políticos de su articulación. Fronteiras: Estudos Midiàticos 8(1), 5-15.

46. Miller, D., \& Slater, D. (2000). The internet: An ethnographic approach. Oxford: Berg.

47. Morley, D. (2005). Pertenencias. Lugar, espacio e identidad en un mundo mediatizado. En L. Arfuch, Pensar este tiempo. Espacios, afectos, pertenencias. (pp. 129-168). Buenos Aires: Paidós.

48. Nieto, G. (2007). La inmigración china en España. Una comunidad ligada a su nación. Madrid: Los libros de la Catarata. 


\section{DISERTACIONES}

ENSAYOS

49. Núñez de Prado, S.(2002). Minorías nacionales y medios de comunicación: una visión de Europa. Ámbitos, (especial 9-10), 9-30.

50. Pogue, H. (2014). Juvenescence: A cultural history of our age. Chicago University Press.

51. Puyana, Y., Motoa, J., \& Viviel, A. (2008). Entre aquí y allá. Las familias colombianas transnacionales. Bogotá: División de Investigaciones de la Universidad de Colombia.

52. Retis, J. (2011). Estudio sobre el consumo cultural de los latinoamericanos en España. Madrid: Observatorio Cultura y Comunicación/Fundación Alternativas.

53. Reverter-Bañon, S. (2006). Las filosofías del ciberfeminismo. En E. Perez-Sedeño (Ed.), Ciencia, Tecnología y Género en Iberoamerica, (pp. 273-284). Madrid: csıc.

54. Rheingold, H. (2004). Multitudes Inteligentes: la próxima revolución social (Smart Mobs). Barcelona: Gedisa.

55. Rodrigo Alsina, M. (1996). Minorías étnicas, identidades y medios de comunicación. Signo y Pensamiento, 29(15), 39-48.

56. Sancho-Gil, J. M., Hernández-Hernández, F., \& Rivera Vargas, P. J. (2016). Visualidades contemporáneas, ciudadanía y sabiduría digital: Afrontar las posibilidades sin eludir las tensiones. Revista Latinoamericana de Tecnología Educativa 15(2), 25-37.

57. Scopsi, C. (2009). Les sites web diasporiques: un nouveau genre médiatique? Tic \& Societé 3(12), 81-100.

58. Serrano-Niza, D. (2011). Mujeres, musulmanas y migrantes: señas de identidad en construcción. En D. Serrano-Niza (Ed.), ¿Visible o invisibles? Mujeres migrantes, culturas y sociedades (pp. 113-124). Madrid: Plaza y Valdés Editores.

59. Sierra-Caballero, F. (2016). Cibercultura, ciudad y nuevos movimientos urbanos. En J. Candón-Mena \& L. Benitez-Eyzaguirre (Eds.), Activismo digital y nuevos modos de ciudadanía: una mirada global (pp. 60-97). Bellaterra: InCom-uaB Publicaciones.

60. Tölölyan, K. (2012). Diaspora studies. Past, present and promise. Working Papers, Oxford: International Migration Institute (IMI).

61. Tortajada, Y. (2009). ¿Qué hay de nuestro aquí? Cómo se perciben en los medios algunas minorías residentes en Cataluña. Zer 14(26), 59-80.

62. Touraine, A. (2005). Un nuevo paradigma. Para comprender el mundo hoy. Barcelona: Paidós.

63. Uribe, A. (2004). As telenovelas mexicanas no México de afuera. En I. Vassalo de Lopes (Coord.), Telenovela, internacionalizaçao e interculturalidades. São Paulo: Ediciones Loyola.

64. Wajcman, J. (2006). El tecnofeminismo. Madrid: Cátedra.

65. Wolf, M. (1994). Los efectos sociales de los media. Barcelona: Paidós.

66. Wulfhorst, C., \& Vianna, E. (2012). Communicating new forms of belonging in the transnational space of Capoeira. En D. Cogo, M. ElHajji, \& A. Huertas (Eds.), Diásporas, migraciones, tecnologías de la comunicación e identidades transnacionales (pp. 85-104). Bellaterra: InCom-uAB Publicaciones.

67. Zanfrini, L. (2007). La convivencia interétnica. Madrid: Alianza Editorial. 